\title{
Characteristics of radio-isotopes for intra-articular therapy
}

\author{
JACQUES INGRAND \\ Service des Isotopes, Hôpital Cochin, Paris
}

Since Ansell, Crook, Mallard, and Bywaters (1963) and Makin and Robin (1964) initiated the method, the use of radioactive colloids in the treatment of chronic synovitis has become routine. The destruction of the inflammatory synovium, called synoviorthèse or synoviolysis, is based on the irradiation of the serosa by colloidal particles, removed from the suspension injected into the articular cavity (Ballabio, Schiavetti, Caruso, and Nerola, 1972; Bonneton, 1972; Webb, Lowe, and Bluestone, 1969).

After injection, the radioactive colloid becomes distributed in the joint in the shape of the synovium, so that a scintigram shows a very similar distribution to that seen in an arthrogram (Fig. 1). The aim of the radiotherapist is to ensure that the energy of the ionizing radiation is absorbed in the synovium only. We must therefore consider the characteristics of the radio pharmaceuticals used for intra-articular therapy, and also the possibility of transfer of energy to tissues which must be preserved from irradiation (Ingrand, 1972; Roucayrol, 1972; Stevenson, Bedford, Hill, and Hill, 1971 b).

The radiation emitted by the colloidal particles may irradiate not only the synovium but also the

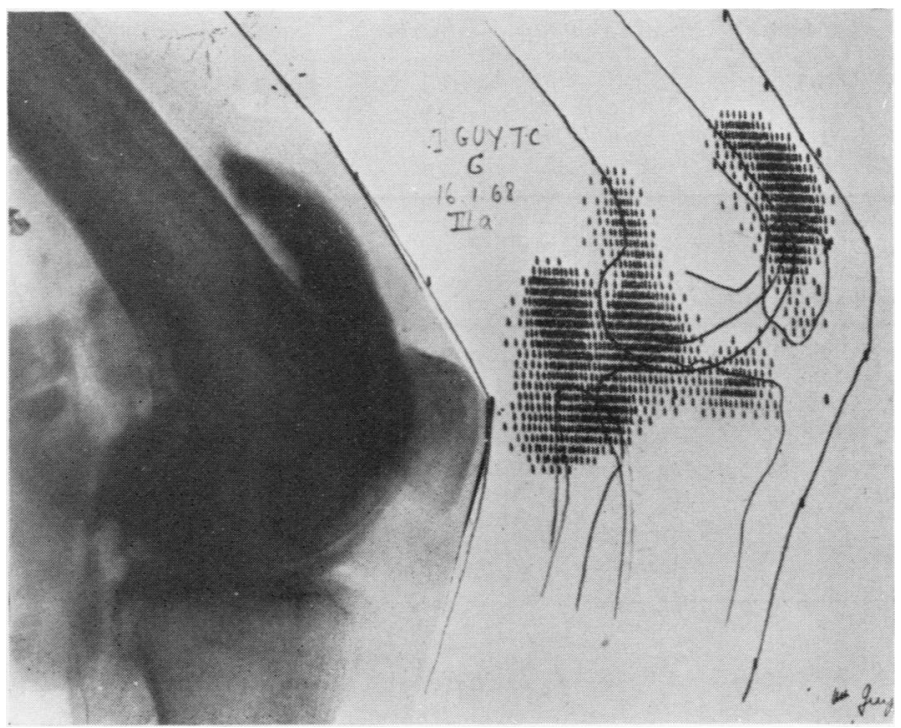

FIG. 1 Knee joint shown by scintigram compared with arthrogram cartilage and bone marrow (Bonneton, 1972), depending on the range of emission of the radioisotope. Fortunately, autoradiographs show that the cartilaginous surface is usually free of radioactivity, which is concentrated in the synovium (Fig. 2). Consequently, the use of a colloid tends to result in localized irradiation, but there remains the possibility of leakage away from the joint via the lymphatic system. These problems have been the basis of a multi-disciplinary study at the Hopital Cochin (Delbarre, Cayla, Aignan, Roucayrol, Menkes, and Ingrand, 1968; Menkes, Aignan, Galmiche, and Le Go, 1972).

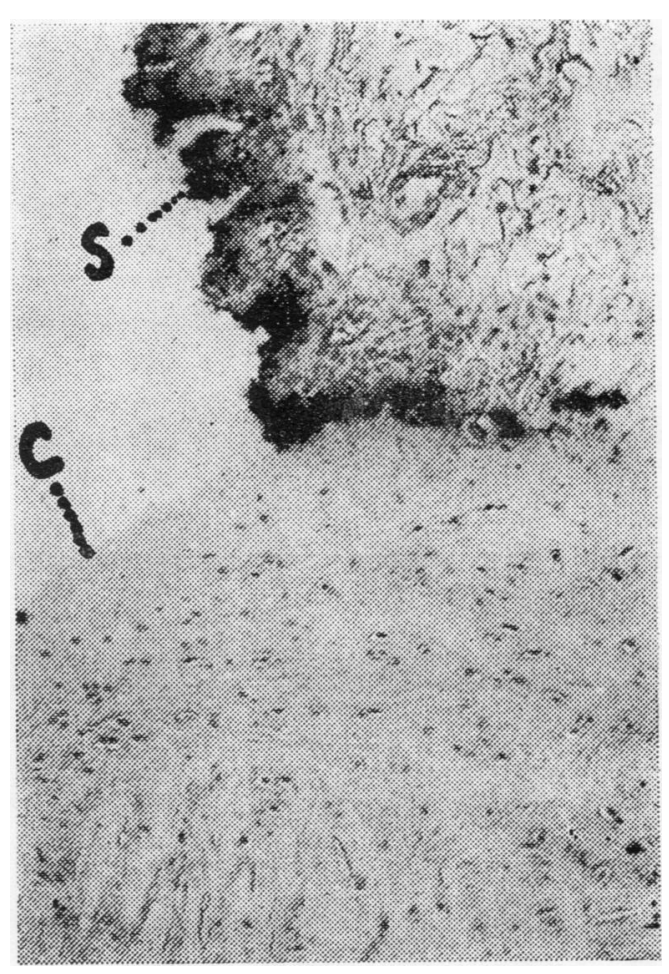

FIG. 2 Autoradiograph of a rabbit knee 72 hrs after injection of ${ }^{169}$ Er citrate. This shows the radioactivity concentrated in the synovium $(S)$ and sparing the cartilage $(C)$.

(From Bonneton, 1972: Rhumatologie, 2, Suppl. 1, Plate 4, Fig. 3, p. 42) 


\section{Physical characteristics of radio-isotopes}

The destruction of the inflammatory synovitis, the biological effect we seek (Aignan and Tesson-Millet, 1972; Ballabio and others, 1972; Guiraudon (1972), depends essentially on the energy absorbed on the surface and inside the serosa. This energy is dissipated along their course by the $\beta$ rays emitted by the radioactive colloidal particles.

There are two important factors: the total energy emitted during the decay of all the radionuclides; and the thickness of the tissue which it is required to irradiate. The total energy depends on the amount of activity injected, on the energy of $\beta$-emission, and on the half-life of the radio-isotope. The thickness of tissue irradiated is related to the energy of $\beta$-emission and to the energy needed to create a pair of ions in the affected area. These data enable us to define a range, along which interactions can take place.

The principal characteristics of the radionuclides used for synoviotherapy are shown in Table I. It must be noted that the $\gamma$-radiation of ${ }^{198} \mathrm{Au}$ is actually a parasitic radiation in this treatment, as its energy is released not only in the joint but also far away from it. Because of this, we have abandoned the use of ${ }^{198} \mathrm{Au}$ and replaced it with rhenium $186\left({ }^{186} \mathrm{Re}\right)$, as the latter has a similar half-life and $\beta$-energy, without the $\gamma$-emission (Bardy, Beydon, and Hégésippé, 1973; Delbarre, Menkes, Aignan, Roycayrol, Ingrand, and Sanchez, 1973).

\section{Characteristics of radiopharmaceuticals}

Radiopharmaceuticals must satisfy certain criteria of purity and general specifications (Cohen, 1970, 1972). Usually these depend on the manufacturer, who must be responsible for the necessary controls and inform the user accordingly. Certain characteristics are important in determining the therapeutic effect or possible adverse side-effects.

\section{(1) Size of colloidal particles}

The question of the most suitable size of the colloidal particles has been examined in reviews of their therapeutic application (Muller, 1962). It is necessary to reach a compromise in determining the size needed for intra-articular therapy. A small diameter $(10 \mathrm{~nm}$.) allows the synovium to be homogeneously irradiated, but seems to be associated with a high frequency of extra-articular spread, whereas a large particle of several hundred $\mathrm{nm}$. may give rise to a variable irradiation of the synovial membrane. To illustrate this, I have tried to relate particle size to the degree of spread found by various authors (Table II). While the various preparations of ${ }^{198} \mathrm{Au}$ are homogeneous, there is considerable variation in the size of the particles of erbium 169 citrate $\left({ }^{169} \mathrm{Er}\right)$, rhenium 186 sulphide $\left({ }^{186} \mathrm{Re}\right)(\mathrm{Fig} .3)$, and yttrium 90 citrate $\left({ }^{90} \mathrm{Y}\right)$.

The specialist in colloidal chemistry must work within narrow margins. He must present a product

Table I Some isotopes used for intra-articular therapy

\begin{tabular}{|c|c|c|c|c|c|c|c|}
\hline \multirow[t]{2}{*}{ Isotope } & \multirow[t]{2}{*}{$\begin{array}{l}\text { Half life } \\
\text { (days) }\end{array}$} & \multirow[t]{2}{*}{ Emission } & \multirow[t]{2}{*}{$\begin{array}{l}\text { Max. energy } \\
\text { of } \beta(\mathrm{MeV})\end{array}$} & \multicolumn{2}{|c|}{$\begin{array}{l}\text { Range in soft tissue } \\
(\mathrm{mm} .)\end{array}$} & \multicolumn{2}{|c|}{$\begin{array}{l}\text { Range in cartilage } \\
(\mathrm{mm} .)\end{array}$} \\
\hline & & & & Mean & Maximum & Mean & Maximum \\
\hline $\begin{array}{l}{ }^{169} \mathrm{Er} \\
{ }^{198} \mathrm{Au} \\
{ }^{186} \mathrm{Re} \\
{ }^{90} \mathrm{Y}\end{array}$ & $\begin{array}{l}9 \cdot 5 \\
2 \cdot 7 \\
3 \cdot 7 \\
2 \cdot 7\end{array}$ & $\begin{array}{l}\beta^{-} \\
\beta^{-}, \gamma \\
\beta^{-}(\gamma) \\
\beta^{-}\end{array}$ & $\begin{array}{l}0.34 \\
0.96 \\
0.98 \\
2.2\end{array}$ & $\begin{array}{l}0 \cdot 3 \\
1 \cdot 2 \\
1 \cdot 2 \\
3 \cdot 6\end{array}$ & $\begin{array}{l}1.0 \\
3.6 \\
3.6 \\
11 \cdot 0\end{array}$ & $\begin{array}{l}0.2 \\
0.9 \\
0.9 \\
2.8\end{array}$ & $\begin{array}{l}0.7 \\
2.7 \\
2.7 \\
8.5\end{array}$ \\
\hline
\end{tabular}

Table II Relation between colloidal size and lymphatic spreading

\begin{tabular}{|c|c|c|c|}
\hline Colloid & $\begin{array}{l}\text { Size } \\
(\mathrm{nm} .)\end{array}$ & $\begin{array}{l}\text { Number of cases } \\
\text { with lymphatic spread }\end{array}$ & Reference \\
\hline${ }^{198} \mathrm{Au}$ & $\begin{array}{l}20 \\
30 \\
30 \\
70 \\
300\end{array}$ & $\begin{array}{l}32 / 90 \\
4 / 18 \\
4 / 21 \\
0\end{array}$ & $\begin{array}{l}\text { Virkkunen and others (1967) } \\
\text { Topp and Cross (1970) } \\
\text { Roucayrol and others (1969) } \\
\text { Makin and Robin (1964) } \\
\text { Correns, Zielke, Unverricht, and } \\
\text { Stiller (1969) }\end{array}$ \\
\hline${ }^{90} \mathrm{Y}$ and ${ }^{169} \mathrm{Er}$ & 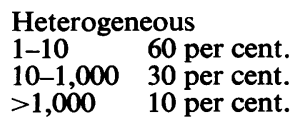 & $11 / 37$ & Delbarre and others (1969) \\
\hline${ }^{186} \mathrm{Re}$ & $5-10$ & $1 / 25$ & Delbarre and others (1969) \\
\hline
\end{tabular}


of which the $\mathrm{pH}$, composition, and ionic strength are physiologically compatible, and at the same time he knows that these conditions will be unfavourable to the delicate process of controlling the growth in diameter of a colloidal particle. Ideally, he will achieve a homogeneous colloid with a particle size around $100 \mathrm{~nm}$. Another problem is that the factors involved in the phenomenon of lymphatic spread are not yet clearly elucidated but, as others will consider this problem later, I will mention only the variability of the individual response and the importance of splinting and resting treated patients (Gumpel, Williams, and Glass, 1972; Ingrand, 1972; Rekonen, Oka, and Ruotsi, 1972; Oka, Isomäki, Rekonen, Ruotsi, and Seppälä, 1972).

One final point about the chemistry of radiocolloids. The majority are made up of an element from classical inorganic chemistry (precious metals and rare earths) but synthetic resins have also been suggested. Their homogeneous size is an advantage, as the radioactive material can be absorbed onto calibrated particles. As they cannot be destroyed in vivo, the resins may later indúce a process of rejection; a process that is more probable with repeated injections.

\section{(2) Radiochemical purity and specific activity}

Every metal transformed to a colloidal form loses the biochemical and physiological properties of its soluble form. For example, colloidal gold has none of the properties of the soluble gold compounds used in chrysotherapy, and colloidal gold, yttrium, erbium, and rhenium should therefore be considered only as radioactive carriers useful at the microscopic level. Radiochemical purity is defined as the ratio of the radioactivity of the element in the desired chemical form to the total radioactivity of the same element in all the chemical forms present (Cohen, 1970). Impurities may be present whose chemical or biological behaviour may differ from that of the desired colloidal form. In the radiocolloids used for synoviotherapy, we are concerned with the presence of soluble components which could induce toxic or allergic reactions (Table III).

Table III Chemical impurities in radiopharmaceuticals used for intra-articular therapy

\begin{tabular}{|c|c|c|}
\hline Isotope & Chemical form used & $\begin{array}{l}\text { Chemical } \\
\text { impurity }\end{array}$ \\
\hline $\begin{array}{l}{ }^{169} \mathrm{Er} \\
{ }^{198} \mathrm{Au} \\
{ }^{186} \mathrm{Re} \\
{ }^{90} \mathrm{Y}\end{array}$ & $\begin{array}{l}\text { Citrate, colloidal } \\
\text { Colloidal gold } \\
\text { Sulphide, colloidal } \\
\text { Citrate, colloidal }\end{array}$ & $\begin{array}{l}\text { Ionic erbium } \\
\text { Chloraurate } \\
\text { Perrhenate } \\
\text { Ionic yttrium }\end{array}$ \\
\hline
\end{tabular}

Radiochemical purity can be checked by chromatography, electrophoresis, or other classical methods. Table IV (overleaf) shows the amounts of soluble components in these radiocolloids, taking as a reference point an activity equal to $10 \mathrm{mCi}$. and the specific activity usually achieved by the manufacturer.

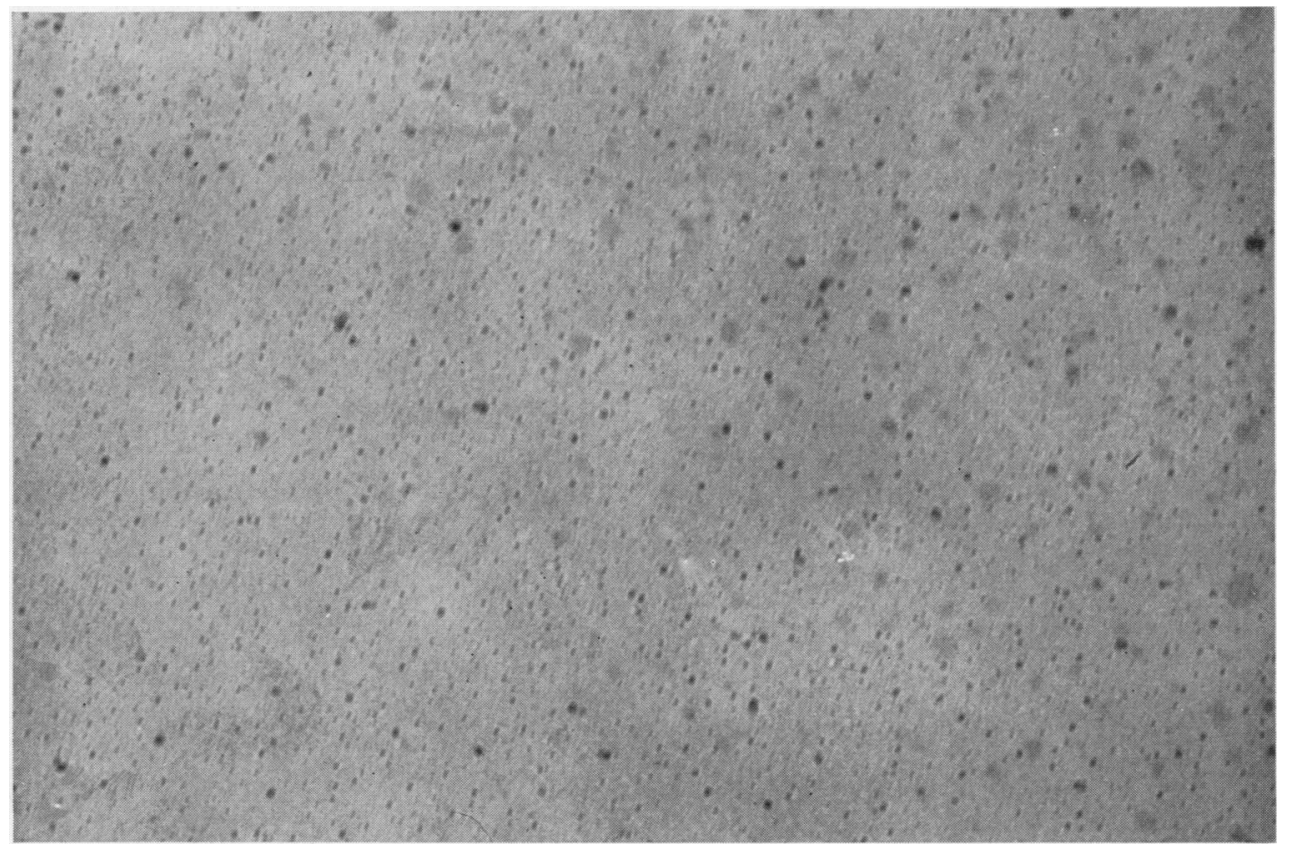

FIG. 3 Electron micrograph of colloidal ${ }^{186}$ Re. $\times 150,000$ 
Table IV Factors in consideration of chemical toxicity of radiocolloids

\begin{tabular}{|c|c|c|c|}
\hline Factor & ${ }^{198} A u$ & ${ }^{90} Y$ and ${ }^{169} \mathrm{Er}$ & ${ }^{186} R e$ \\
\hline $\begin{array}{l}\text { Specific activity }(\mathrm{Ci} / \mathrm{g} .) \\
\text { Total amount of element in } 10 \mathrm{mCi}(\mathrm{mg} .) \\
\text { Non-colloidal element } \\
\text { Total amount of non-colloidal element in } 10 \mathrm{mCi} \\
\text { LD50 (animal) }\end{array}$ & $\begin{array}{l}10 \\
1 \\
<1 \text { per cent. } \\
<10 \mathrm{mg} . \\
\text { High }\end{array}$ & $\begin{array}{l}0.2 \\
50 \\
<1 \text { per cent. } \\
<0.5 \mathrm{mg} \text {. } \\
\text { Intravenous } 35 \mathrm{mg} . / \mathrm{kg} \text {. } \\
\text { Intraperitoneal } 225 \mathrm{mg} . / \mathrm{kg} \text {. }\end{array}$ & $\begin{array}{l}40 \\
0 \cdot 2 \\
<1 \text { per cent. } \\
<2 \text { mg. } \\
\text { High }\end{array}$ \\
\hline
\end{tabular}

With the rare earths and rhenium, where the percentage of soluble component is less than 1 per cent., the amount available to produce a pharmacological effect is negligible. However, the limit of 1 per cent. will certainly need modification for gold, as there may be severe allergic reactions to the soluble forms. Menkes and others (1972) described a reaction after a second injection of ${ }^{198} \mathrm{Au}$ in a patient with previous gastrointestinal intolerance to gold. The first injection was uneventful, but 3 weeks after the second a typical gold-type skin rash and a nephrotic syndrome occurred.

\section{(3) Purity of radionuclide}

Only the radio-isotope stated must be present in the radiopharmaceutical. This is an important condition, as the impurities (Table V) could be $\beta$-emitters with a long half-life, or $\gamma$-emitters, or could alternatively be different radio-isotopes not absorbed by the synovium. The purity of the radionuclide is most often assessed by $\beta$ or $\gamma$ spectrometry on a sample taken as it comes out of the nuclear reactor and is tested during its physical decay.

\section{(4) Concentration of radioactivity}

According to the radio-isotope, there may be variations in concentration of from 1 to $15 \mathrm{mCi}$./ $/ \mathrm{ml}$. Generally the concentration does not affect its use, except when treating joints of small potential volume such as the proximal interphalangeal joints, in which the use of solutions of concentrations greater than $5 \mathrm{mCi} . / \mathrm{ml}$. is necessary.

\section{(5) Biological properties}

The preparation must be delivered in a sterile and non-pyrogenic form, and subsequent handling must preserve its sterile condition. It is also strongly recommended that solutions should be as close as possible in $\mathrm{pH}$ and osmolality to normal synovial fluid to reduce the frequency of painful reactions.

Considerations on the intra-articular use of radioactive colloids

\section{(1) Problems of dosimetry}

As in any other irradiation, that of an inflamed synovium must be adequate, and well distributed in time and space, and must not damage other radiosensitive organs.

In this field, it is not easy to define what is an adequate radiation dose. The absorbed dose, calculated in rads, depends not only on the radioisotope (energy of $\beta$-emission and half-life) and the injected amount (activity in $\mathrm{mCi}$.), but also on the final distribution of the radioactivity (shape and volume). This latter is a factor beyond our control. As the particles are taken up from the synovial fluid in the first hours after the injection, the shape of their distribution varies very greatly from patient to patient (Figs 4, 5, and 6), while the thickness of the pannus and the way the membrane is thrown into folds influence the volume of tissue irradiated. Both of these factors influence the evaluation of the therapeutic effect.

It is therefore easy to understand that on the whole the determination of the radiation dose given to the patient has been empirical. We now know that the therapeutic effect of $1 \mathrm{mCi}$. ${ }^{198} \mathrm{Au}$ is not enough in the knee (Fellinger and Schmid, 1952), whereas

Table V Radio-nuclidic impurities in radio pharmaceuticals used for intra-articular therapy

\begin{tabular}{|c|c|c|c|c|}
\hline \multirow[t]{2}{*}{ Isotope } & \multirow[t]{2}{*}{ Production process } & \multirow[t]{2}{*}{ Other isotopes probably present } & \multicolumn{2}{|c|}{ Physical data } \\
\hline & & & Half life & Type of decay \\
\hline${ }^{169} \mathrm{Er}$ & ${ }^{168} \operatorname{Er}(\mathrm{n}, \gamma){ }^{169} \mathrm{Er}$ & $\begin{array}{l}{ }^{171} \mathrm{Er}<0.01 \text { per cent. } \\
{ }^{171} \mathrm{Tm}\end{array}$ & $\begin{array}{l}7.5 \mathrm{hrs} \\
1.9 \mathrm{yrs}\end{array}$ & $\begin{array}{l}\beta^{-}, \gamma \\
\beta^{-}, \gamma\end{array}$ \\
\hline${ }^{198} \mathrm{Au}$ & ${ }^{197} \mathrm{Au}(\mathrm{n}, \gamma){ }^{198} \mathrm{Au}$ & ${ }^{199} \mathrm{Au}<5$ per cent. & $3 \cdot 1$ days & $\beta^{-}, \gamma$ \\
\hline${ }^{186} \mathrm{Re}$ & ${ }^{185} \operatorname{Re}(\mathrm{n}, \gamma){ }^{186} \operatorname{Re}$ & ${ }^{188} \mathrm{Re}<0.04$ per cent. & $17 \cdot 5 \mathrm{hrs}$ & $\beta^{-}$ \\
\hline${ }^{90} \mathrm{Y}$ & ${ }^{89} \mathrm{Y}(\mathrm{n}, \gamma)^{90} \mathrm{Y}$ & - & - & - \\
\hline
\end{tabular}

n= neutron 


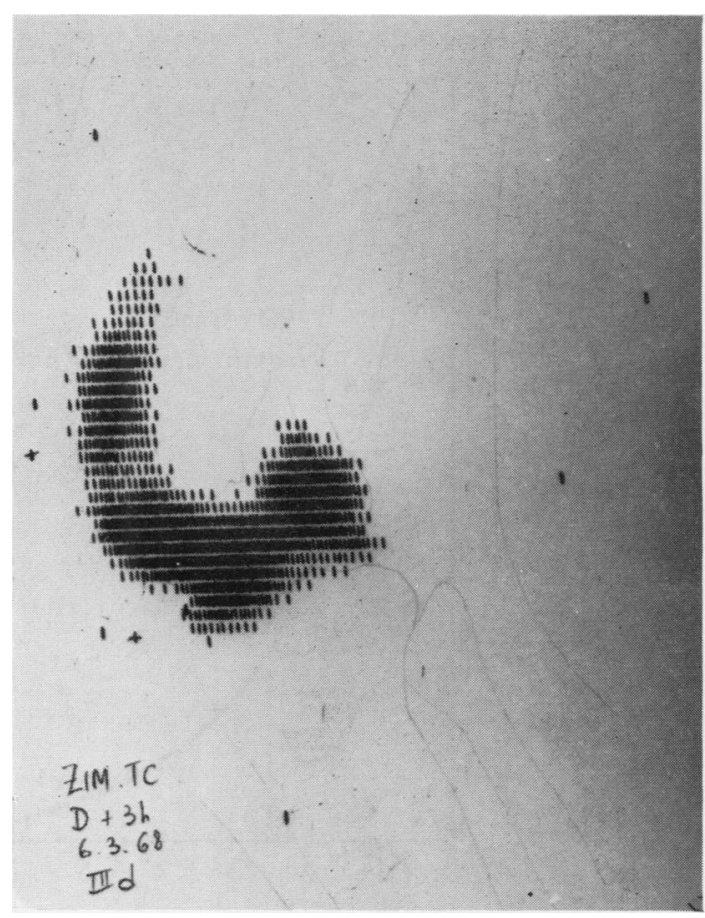

FIG. 4 Normal knee. Lateral view, showing distribution of radiocolloid in the cavity

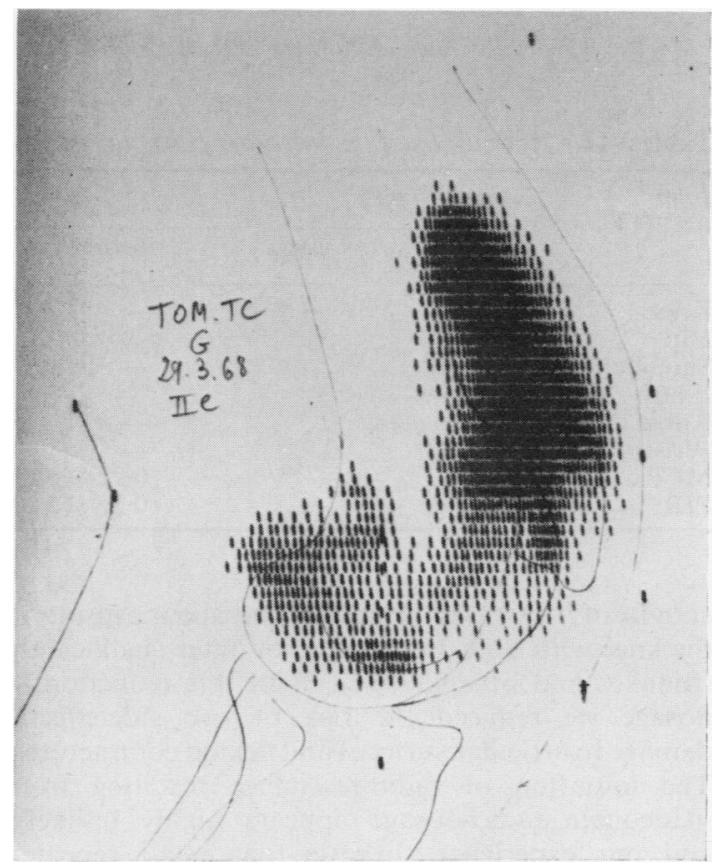

FIG. 5 Pathological knee (lateral view)

$10 \mathrm{mCi}$. ${ }^{90} \mathrm{Y}$ may damage the articular surfaces (David-Chaussé, Reboul, Dehais, and Gillet, 1972) or cause flexion contractures of the knee (Menkes

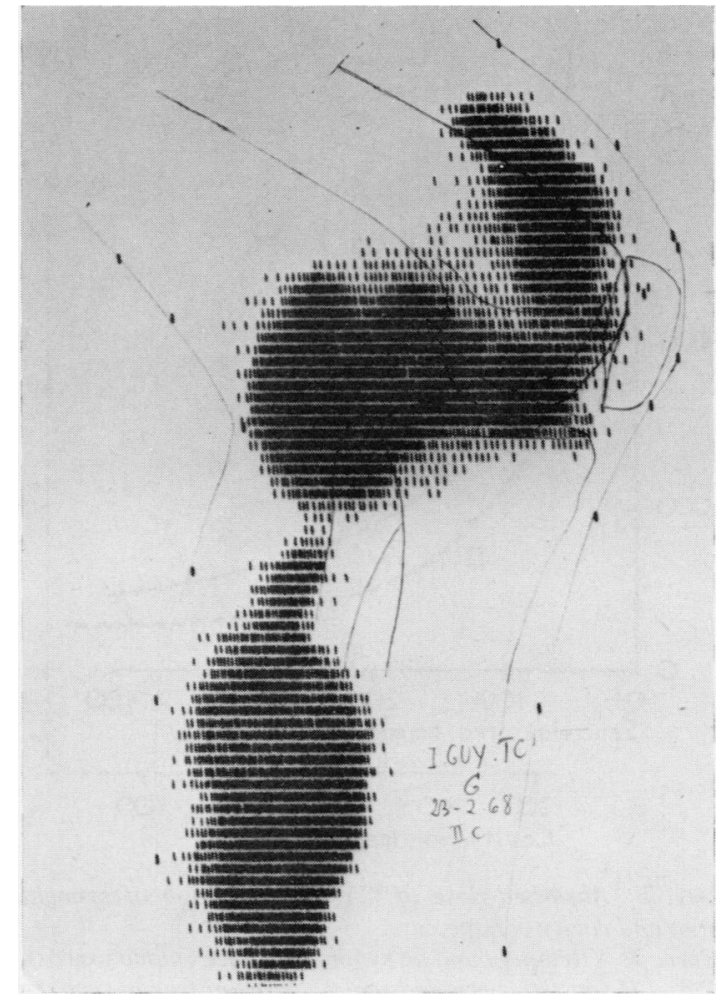

FIG. 6 Pathological knee with Baker's cyst (lateral view)

and others, 1972). Several authors (Gumpel and others, 1972; Rekonen and others, 1972) have attempted to calculate the absorbed dose by analysing simple schemes of distribution. Oka's approach is represented in Figs 7 and 8 (overleaf). In the first he has calculated the absorbed dose in terms of ${ }^{90} \mathrm{Y}$ bound on the synovial membrane (plane source) and suspended in synovial fluid (volume source); the second shows the variation of the absorbed dose with the depth of the tissue.

Using the classical equation for $\beta$-dosimetry (Loevinger, Japha, and Brownell, 1956) and the $10,000 \mathrm{r}$ dose known to be sufficient, we have calculated the tissue concentration of several isotopes. It is only relative, in that it assumes homogeneous distribution of radioactivity in the synovium without extra-articular leakage, but it may nevertheless be of use as a reference when replacing one radio-isotope with another of different physical characteristics (Table VI).

\section{(2) Current practice at the Hôpital Cochin}

The current dosimetry of the various radio pharmaceuticals used at the Hopital Cochin is shown in Table VII; these are based on practical experience. It will be seen that the very powerful $\beta$ ray of ${ }^{90} \mathrm{Y}$ is 


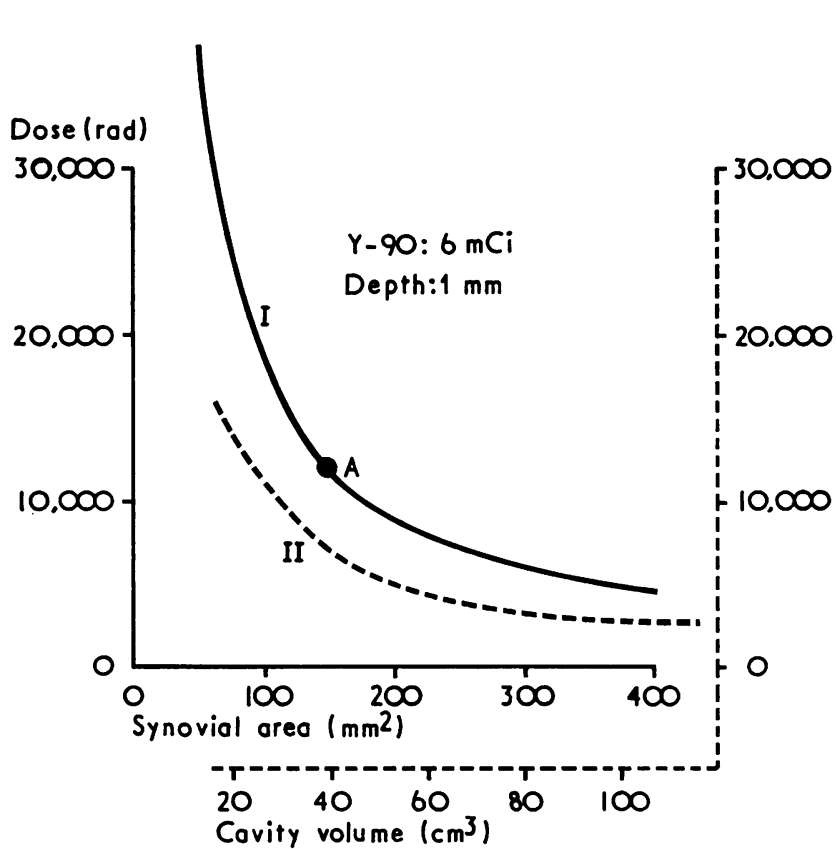

FIG. 7 Absorbed dose of ${ }^{90} Y$ as a function of synovial area and cavity volume.

Curve I: Yttrium bound on synovial surface (plane source). Curve II (dotted curve and scale): Yttrium free in synovial fluid (volume source).

(From Rekonen, Oka, and Ruotsi (1972), p. 55, Fig. 3)

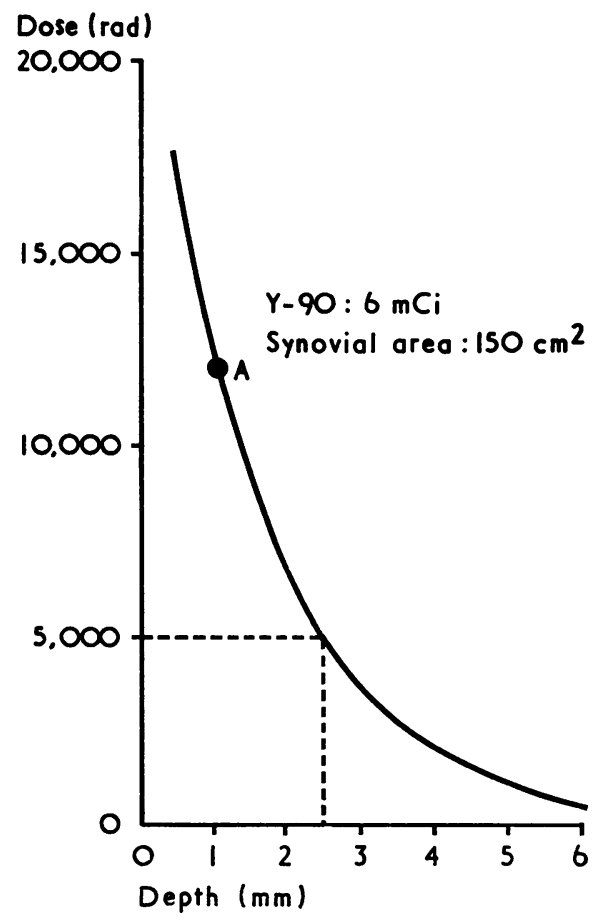

FIG. 8 Absorbed dose of ${ }^{90} Y$ as a function of tissue depth, corresponding to point $A$ of curve in Fig. 7.

(From Rekonen and others (1972), 55, Fig. 4)
Table VI Radioactive tissue concentrations giving absorbed dose of 10,000 $r$ after complete decay

\begin{tabular}{|c|c|c|}
\hline \multicolumn{2}{|l|}{ Isotope } & \multirow{2}{*}{$\begin{array}{l}\text { Tissue concentration } \\
(\mathrm{mCi} / \mathrm{mg} .)^{*}\end{array}$} \\
\hline Half-life & Mean $\beta$ energy $(\mathrm{MeV})$ & \\
\hline 3 days & $\begin{array}{l}0 \cdot 11 \\
0 \cdot 32 \\
0.90\end{array}$ & $\begin{array}{l}0.4 \\
0.13 \\
0.05\end{array}$ \\
\hline 9 days & $\begin{array}{l}0.11 \\
0.32 \\
0.90\end{array}$ & $\begin{array}{l}0.13 \\
0.05 \\
0.02\end{array}$ \\
\hline
\end{tabular}

* Assuring homogeneous distribution of radioactivity.

used only in the knee, that ${ }^{186} \mathrm{Re}$ has replaced ${ }^{198} \mathrm{Au}$ in all the applications of the latter, and that ${ }^{169} \mathrm{Er}$ is used only in the finger joints. This scheme is based on two principles: first to use a $\beta$-emitter the energy of which is suited to the thickness of the synovial membrane (two cases of cutaneous necrosis were recorded using ${ }^{90} \mathrm{Y}$ in finger joints: Menkes and others, 1972), and secondly to reduce the injected radioactivity to the minimum amount needed for therapeutic effect. Accordingly, in 1971, we were able to halve the injected
Table VII Activity used for intra-articular therapy

\begin{tabular}{|c|c|c|c|}
\hline \multirow[t]{2}{*}{ Joint } & \multicolumn{3}{|c|}{ Activity $(m C i)$} \\
\hline & ${ }^{90} Y$ & ${ }^{186} \mathrm{Re}$ & ${ }^{169} \mathrm{Er}$ \\
\hline Knee & $3-4$ & - & - \\
\hline & - & 3 & - \\
\hline Shoulder & - & 2 & 一 \\
\hline Elbow & - & 2 & - \\
\hline Ankle & - & 2 & - \\
\hline Wrist & 一 & $1-2$ & $\overline{0.25} 0.5$ \\
\hline $\begin{array}{l}\text { MCP } \\
\text { PIP }\end{array}$ & 二 & 二 & $\begin{array}{l}0.25-0.5 \\
0.25-0.5\end{array}$ \\
\hline
\end{tabular}

activity of ${ }^{198} \mathrm{Au}$ and ${ }^{90} \mathrm{Y}$ and the therapeutic results in the knee with 6 or $3 \mathrm{mCi}$. did not differ significantly (Menkes and others, 1972). With this reduction in dosage we reduced the risk of two side-effects: damage to articular surfaces and flexion contractures. The initiation of radio-resistance resulting from inadequate radio-dosage appears highly unlikely, and our experience suggests that small repeated doses are better than a single large dose. However, it is also reasonable to use a single injection, as we often do in order to provide more rapid and sure relief for the patient. 
(3) Problems raised by the intra-articular injection itself

\section{CHOICE OF PATIENTS}

Certain patients should not be accepted for treatment unless it is absolutely unavoidable. These include women who could possibly be pregnant; young patients, especially where the hip is concerned; patients with severe destruction of the articular surfaces; patients with haemophiliac arthropathy. In all the doubtful cases, and especially the younger ones, a tracer dose of $50-100 \mu \mathrm{Ci}$. will test the patient's reaction and give information on extra-articular spread.

\section{METHOD OF INJECTION}

The injection is usually composed of local anaesthetic, the radiocolloid variably diluted with saline, and a corticosteroid. Except in the case of the knee, $x$-ray contrast medium is used to check the position of the needle in the joint and to show any communication with serous bursae or with the synovial sheath. When removing the needle, back-flow at the point of injection through the skin and underlying tissues of even a very small amount of concentrated radioactivity may be the direct cause of radionecrosis. To avoid this a three-way tap is used and the needle is flushed before removal with saline or other rinsing solution.

\section{IMMOBILIZATION}

The final and most essential precaution is to immobilize the treated joint for 48 hours. This simple operation greatly reduces the amount of radioactivity which may escape.

\section{Assessment}

An objective assessment of the therapeutic result may be obtained by arthroscintigraphy with technetium 99 M pertechnetate (Delbarre, Menkes, Prin, Roucayrol, Ingrand, Rebut, and Aignan, 1971).

\section{Conclusion}

In 1973, radioactive intra-articular therapy has clearly passed beyond its infancy as far as radio pharmaceuticals are concerned. The rheumatologist now has a rich stock of $\beta$-emitters, well adapted to the problems of the joints to be treated. The characteristics of the radiocolloids have been greatly improved, except perhaps for the size of the colloidal particles.

In the future, research in this field should be focused on the following interesting problems: finding new and better inert substrates for radioactivity and synthesizing those molecules which possess a selective tropism for the pathological cellular elements of the synovial membrane.
I am greatly indebted to Madame Catherine Ingrand and Miss Cliona Daly for translating this text, and to Dr. Michael Gumpel for revising it.

\section{Discussion}

DR. ROBERTS I should like to ask Professor Ingrand about the results in his patients following the injection of the cocktail that he describes. It may be the experience of others that intra-articular steroids produces benefit which is temporary and I wonder if the considerable reduction in dose that you were able to achieve may in fact have been at the expense of a reduction in the duration of the benefit brought about by the introduction of a small amount of corticosteroids into the joint.

PROF. INGRAND The experiments on dose of radiocolloids were made using the same amount of corticosteroid, whether we used 3 or $6 \mathrm{mCi}$.

DR. ANDREWS You showed some beautiful pictures of the distribution of radioactivity in knees. Have you any data on whether the distribution of activity within a given joint is in any way related to the route of injection?

PROF. ING RAND I suppose the route of administration is not very important in the knee, because we can approach it from the outer or the inner aspect. Pouches and bursae do not always communicate with the general synovial cavity. In this case we are obliged to inject twice, first in the normal cavity and, if after scanning we see there is no activity in the nearby cavity, we must inject directly into the cavity. Nevertheless, radioactivity is homogeneously distributed in most cases, even when the patient is immobilized. There is a spontaneous diffusion of the radiocolloid in the synovial fluid in which histocytic reactions occur. Sometimes there appear to be regions without histocytic activity and in these cases one may anticipate a less satisfactory result of the treatment. But, as happens with many immunological reactions, we may often have good results even if the theoretical result does not seem to be good.

MR. LAURENCE In relation to those scintigraphic pictures which were very beautiful, I wondered if you had any information whether the intensity of uptake by the synovium was related to the virulence of the inflammation. I ask this because perhaps those areas which were able to take up the isotope most easily and in highest doses might not be the areas responsible for the effusion, but were the areas more physiological in their function of absorption; therefore possibly you were getting a therapeutic dose in the areas where the synovium was less severely diseased. Have you any information on this topic?

PROF. INGRAND I have tried to compare in the same patients the scintigraphic pattern of radioactivity after intra-articular injection of a radiopharmaceutical and after intravenous injection of technetium $99 \mathrm{M}$ pertechnetate $\left.{ }^{99 \mathrm{~m}} \mathrm{Tc}\right)$, or after intra-articular injection of

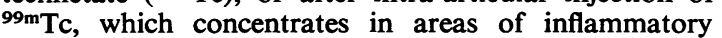
activity. Sometimes there is a good correlation between the two, but in other cases there are marked differences in their distribution, but even in this theoretically unfavourable condition there can be a good therapeutic effect. 